\title{
Stress-Strain Model for Reactive Powder Concrete Confined by Steel Tube
}

\author{
Hua Luo ${ }^{1}$, Weiwei Wang ${ }^{1 * *}$, Lian Shen ${ }^{2}$ and Guanghui Wang ${ }^{1}$ \\ ${ }^{1}$ College of Civil Engineering and Architecture, Hunan Institute of Science and Technology, Yueyang 414000, China \\ ${ }^{2}$ Department of Civil and Environmental Engineering, Louisiana State University, Baton Rouge, LA 70803, USA
}

Received 19 October 2016; Accepted 29 March 2017

\begin{abstract}
The reliable prediction using nonlinear methods for reactive powder concrete (RPC)-filled steel tube columns relies on the use of an accurate model for core RPC. However, the existing stress-strain model for core concrete has some disadvantages, such as a complicated form, excessive unknown parameters, and inapplicability to RPC. To establish a stress-strain model for RPC confined by a steel tube in finite element analysis (FEA), compressive experiments were carried out on RPC-filled steel tube columns. Calculation formulas of the theory-character parameters (peak stress and peak strain) for RPC-filled circular steel tube were also presented, and a multiparameter stress-strain model for RPC confined by steel tube was proposed based on the existing constitutive model for concrete-filled steel tube. Several nonlinear finite element models were established with ABAQUS, applying the proposed stress-strain model for RPC confined by a steel tube, and the calculating results were compared with the test results of six groups of RPC-filled steel tube stub columns. Experimental results demonstrate that the confining pressure varies from $14.43 \mathrm{MPa}$ to $32.85 \mathrm{MPa}$; hence, the core RPC is in a low confining pressure state. The peak strength of core RPC increases with the increasing material strength and hoop coefficient. Thus, hoop coefficient and material strength are key parameters that affect the peak strength of the core RPC. The load-strain curves of the specimens obtained by experiments and finite element simulation are in good agreement, thereby verifying the reliability of the proposed model in this study. This study provides a theoretical reference for FEA and calculation of an RPC-filled steel tube structure.
\end{abstract}

Keywords: Reactive Powder Concrete; Stress of steel tube; Peak stress; Peak strain; Constitutive model

\section{Introduction}

High-strength concrete columns are largely applied to the construction of a large number of high-rise buildings. However, stronger concrete is generally more brittle; thus, the concrete-filled steel tube system is proposed. This system is an effective means to avoid explosive failure of high-strength concrete and reduce the cross-sectional size of columns. A reactive powder concrete (RPC)-filled steel tube system is formed by filling a steel tube with ultra-high performance RPC. An RPC-filled steel tube system has ultra-high carrying capacity and excellent deformation performance; hence, it has broad application potential in super high-rise structures and large span bridges. However, mutual force is generated in the interface under external load because of the different transverse deformation performances between the steel tube and the core RPC. Hence, the core RPC is subjected to lateral pressure, which converts RPC into triaxial compression from uniaxial compression. In the design and verification of the bearing capacity of the RPC-filled steel tube structure, if the uniaxial compressive or tensile strength is adopted, then the use of the lower two-axis and triaxial compressive strength or higher multi-axis tensile compression strength is inappropriate. Therefore, accurate evaluation of the stress

*E-mail address: 13873065820@163.com

ISSN: 1791-2377 @ 2017 Eastern Macedonia and Thrace Institute of Technology. All rights reserved. state of the core RPC confined by the steel tube and introducing a reasonable stress-strain relationship of the core RPC are necessary.

Ordinary concrete is composed of coarse aggregates, fine aggregates, and cementitious material. The interface between cement and coarse aggregates is uneven, limiting the strength of ordinary concrete. Compared with the traditional ordinary concrete, RPC minimizes the internal porosity and microcracks inside the material, obtains high strength and durability by improving the fineness and activity of the components [1-3]. Therefore, the mechanical properties of RPC are different from those of the ordinary concrete, and the existing constitutive model of ordinary concrete is not suitable for the RPC-filled steel tube structure.

With the development of computer technology, finite element analysis (FEA) has become an effective means to study the performance of RPC-filled steel tube structure [45]. To analyze the mechanical properties of RPC-filled steel tube through numerical analysis methods, many scholars presented constitutive models to describe the core concrete, such as elastoplastic theory model [6-8], elastic-fracture theory model [9], and endochronic theory model [10]. Researchers have analyzed the mechanical properties of concrete-filled steel tubular members under axial compression, pure bending, pure twisting, compression, and bending based on these theories. Satisfactory and useful results for in-depth study of the working mechanism of concrete were achieved. However, the stress-strain model for 
Hua Luo, Weiwei Wang, Lian Shen and Guanghui Wang/

Journal of Engineering Science and Technology Review 10 (2) (2017) 122-131

core concrete has the following disadvantages: the model is complicated, has excessive unknown parameters, and is inapplicable to RPC. Moreover, in the load-deformation relationship analysis of concrete-filled steel tube using FEA, the elements must be sufficiently thin because the thickness between the steel tube and the core concrete has a considerable difference. An excessively complex constitutive model results in a large amount of computation, which makes the theoretical analysis uneconomical and inconvenient

This study constructs a comprehensive parameter constitutive model for core RPC confined by the steel tube by analyzing a large amount of experimental data. This study aims to establish a foundation for further numerical analysis of RPC-filled steel tube structure.

\section{State of the art}

Research on RPC-filled steel tube is still in the initial stage given that the RPC-filled steel tube is a new type of steel tube and concrete composite structure. Thus far, domestic and foreign scholars have performed many studies on the performance of RPC-filled steel tube structure through experimental and FEA methods. They provided some calculation methods that are suitable for engineering design. However, these studies mainly focused on exploring the failure mode, the ultimate bearing capacity, and the loaddeformation curves of the structure. Hua et al. [4] conducted experimental research on the influence of two different loading methods on the behavior of RPC-filled steel tube columns subjected to axial load, namely, full-section loading and core-concrete loading. A nonlinear finite element model was established to simulate the axial compression process of RPC-filled steel stub columns. Results indicated that, with the use of two different loading methods, the stress development processes were different, but the ultimate load carrying capacities were similar. Yan et al. [5] tested two sets of RPC-filled steel tube columns by using the push-out method. A nonlinear finite element model was established to investigate the bond behavior at the interface between the steel tube and RPC. Test results showed that the push-out test data, including the bond-slip curve and the bond load, were similar to those of ordinary concrete-filled steel tube (CFST) columns. Min et al. [11] proposed a unified formula to calculate the axial load bearing capacity of CFST columns with either circular or polygonal sections, considering the interface bonding performance and size effect based on the unified strength theory and thick-walled cylinder theory. Parametric studies were conducted to investigate the influence of the unified strength theory parameter, confinement index, and RPC strength. Practical calculation formulas for axial compression bearing capacity were proposed based on statistical analysis. Ji et al. [12] performed experimental research on the influence of different slenderness ratios and hoop coefficients with a slenderness ratio on RPC-filled circular slender steel tube columns. Results indicated that the columns show a overall elastic buckling accompanied by local buckling for specimens with lower slenderness. The specimens with lower slenderness showed more ductile failure characteristics, and the failure mode turned into buckling with increasing slenderness ratio. Guo et al. [13-15] conducted experimental research on four large-scale RPCfilled steel tube column specimens to investigate the blastresistant capacities of RPC-filled steel tubular columns.
After exposure to fire, the time history curves of reflected overpressure of blast load and displacements and strains of specimens were obtained. Results showed that the RPCfilled steel tubular columns maintained an excellent blast resistance after exposure to fire, and the core RPC column could be effectively constrained by steel tube under explosion load. In previous studies, the RPC and steel tube were considered as a whole to analyze the failure mode and the ultimate bearing capacity of the structure, the mechanical mechanism of the material has not been discussed. The mechanical performance of the RPC material must be studied to determine the working mechanism of the RPCfilled steel tube structure and the interaction between steel tube and RPC.

The RPC in the steel tube is in a complex stress state. To explore the mechanism of its failure, many scholars studied the uniaxial and multi-axis constitutive relations of RPC. Prabha et al. [16] constructed a complete stress-strain curve for RPC through experiments. The effect of material composition on the stress-strain behavior and the compression toughness was presented in the study. The optimum fiber content was $2 \%-3 \%$. Zheng et al. [17-18] presented the stress-strain curves of RPC specimens in compression tests at increasing temperatures to study the fire resistance of RPC. Yu et al. [19] studied the failure mode, strength characteristics, and deformation law of RPC through conventional triaxial compression tests of RPC cylinder specimens under different confining pressures. Results indicated that the RPC failure mode under conventional triaxial compression was splitting failure given that the confining pressure was less than or equal to $60 \mathrm{MPa}$. When the confining pressure reached $65 \mathrm{MPa}$, RPC failure showed squeeze flow characteristics. The shapes of the stress-strain curves of RPC specimens were basically similar under different confining pressures, but the growth rate of RPC triaxial compressive strength along with the increase in confining pressure was lower than that of ordinary concrete. Wang et al. [21] performed experimental research on the effect of confinement on ultrahigh-strength concrete subjected to various confining pressures from $25 \mathrm{MPa}$ to 400 $\mathrm{MPa}$. Brittle-to-ductile failure transition was observed between confining pressures of 100 and $200 \mathrm{MPa}$. On the basis of the test data, a failure surface developed, which described the constitutive behavior of the ultrahigh-strength concrete under a multiaxial stress state. Noori et al. [21] studied the behavior of a steel fiber-reinforced cementitious mortar in a triaxial compression condition and provided empirical equations to predict the peak axial stress and the corresponding strain of the RPC materials.

In this analysis, RPC is under an active lateral pressure. However, in the RPC-filled steel tube structure, the lateral confinement pressure is generated only when the lateral deformation of the RPC exceeds that of the steel tube, and the core RPC is subjected to the passive lateral confinement pressure, which varies with load. The compression condition of core RPC is gradually changed from uniaxial to triaxial compression. Therefore, studying the constitutive relation of RPC under the constraint of steel tube is necessary. Thus far, scholars at home and abroad have conducted many studies on the constitutive relationship of core concrete confined by a steel tube. $\mathrm{Wu}$ et al. [22] presented a model to predict the complete stress-strain curve of concrete subjected to triaxial stresses by axial load and lateral force. Lai et al. [23] assembled an experimental database that contained 422 uniaxial compression test results of CFST columns and proposed a theoretical model to predict the uniaxial behavior 
of circular CFST columns. The steel tube and ordinary concrete show good collaboration while the collaboration between steel tube and RPC is worse; hence, the constitutive model for ordinary concrete-filled steel tube structure is not applicable to an RPC-filled steel tube structure.

To address the shortcomings of the existing studies, this study proposes a stress-strain model for the core RPC, which can be used in FEA. Dimensionless stress-strain curves of the RPC-filled steel tube columns under axial compression were derived through characteristic parameter fitting. The polynomial curve equation indicates that the stress-strain curves were divided into two sections, namely, the ascending and descending sections, and the characteristic parameters (peak stress, peak strain) for stress-strain curves were derived through a large number of tests. Then the dimensionless stress-strain curve of the RPC-filled steel tube was fitted for further numerical analysis of the RPC-filled steel tube structure.

The remainder of this study is organized as follows: Section 3 describes the experimental design and the finite element modeling parameters. Section 4 discusses the new stress-strain model and the applicability of the method through FEA studies. Section 5 summarizes the conclusions.

\section{Methodology}

\subsection{General framework}

\subsubsection{Design and manufacture of specimens}

Twelve RPC-filled steel tube stub column tests were conducted, as listed in Table.1, which shows the test information of the specimens. Where $D=$ the outer diameter of the steel tube; $t=$ the thickness of the steel tube; $L=$ the length of the column; $f_{\mathrm{y}}=$ the yield strength of the steel tube; $A_{\mathrm{s}}=$ the cross sectional area of the steel tube; $A_{\mathrm{c}}=$ the cross sectional area of the RPC; $\xi=$ hoop coefficient. The tests are performed to investigate the influence of the parameters of loading method, the strength of RPC, and the hoop coefficient on the failure modes, ultimate bearing capacity, and load-deformation curves of RPC-filled steel tube columns subjected to axial compression.

Table 1. Main parameters of specimens

\begin{tabular}{|c|c|c|c|c|c|c|}
\hline Specimen & $D \times t \times L / \mathrm{mm}$ & $f_{\mathrm{y}} / \mathrm{MPa}$ & $A_{\mathrm{s}} / \mathrm{mm}^{2}$ & $f_{\mathrm{c}} / \mathrm{MPa}$ & $A_{\mathrm{c}} / \mathrm{mm}^{2}$ & $\xi$ \\
\hline \begin{tabular}{|l|}
$\mathrm{G}-1$ \\
$\mathrm{G}-2$ \\
\end{tabular} & $121 \times 6 \times 450$ & 316.0 & 2167.7 & 75 & 9331.3 & 0.979 \\
\hline \begin{tabular}{|l|} 
G-3 \\
G-4 \\
\end{tabular} & $102 \times 4 \times 450$ & 291.4 & 1231.5 & 75 & 6939.8 & 0.689 \\
\hline \begin{tabular}{|l|} 
G-5 \\
G-6
\end{tabular} & $152 \times 5 \times 450$ & 321.6 & 2309.1 & 75 & 15836.8 & 0.625 \\
\hline $\begin{array}{l}\text { A-11 } \\
A-12\end{array}$ & $121 \times 6 \times 450$ & 316.0 & 2167.7 & 100 & 9331.3 & 0.734 \\
\hline$\frac{A-13}{A-14}$ & $102 \times 4 \times 450$ & 291.4 & 1231.5 & 100 & 6939.8 & 0.517 \\
\hline$\frac{A-15}{A-16}$ & $152 \times 5 \times 450$ & 321.6 & 2309.1 & 100 & 15836.8 & 0.469 \\
\hline
\end{tabular}

\subsubsection{Mechanical properties of materials}

Specimens are produced according to the standard material test requirements, and tensile tests are performed according to "tensile testing method for metallic materials at room temperature" (GB/T228.1-2010). The average yield strength, ultimate tensile strength, elastic modulus, and Poisson's ratio are shown in Table.2, and the failure modes of the tensile test specimens are shown in Fig.1. Where $f_{\mathrm{u}}=$ the ultimate strength of the steel; $E=$ elastic modulus of the steel.

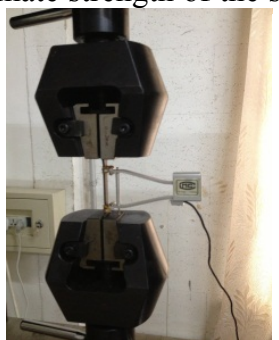

(a) Tensile test

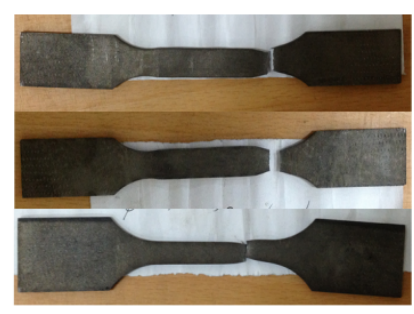

(b) Specimen failure
Fig. 1. Tensile test failure diagram

Table 2. Mechanical properties of steel

\begin{tabular}{c|c|c|c|c}
\hline $\boldsymbol{D} \times \boldsymbol{t} / \mathbf{m m}$ & $f_{\mathrm{y}} / \mathbf{M P a}$ & $f_{\mathrm{u}} / \mathbf{M P a}$ & $\boldsymbol{E} / \mathbf{M P a}$ & Poisson's ratio \\
\hline $121 \times 6$ & 351 & 509 & $2.05 \times 10^{5}$ & 0.28 \\
\hline $102 \times 4$ & 330 & 494 & $2.02 \times 10^{5}$ & 0.29 \\
\hline $152 \times 5$ & 338 & 482 & $2.03 \times 10^{5}$ & 0.28 \\
\hline
\end{tabular}

\subsubsection{Test and loading scheme}

Figure. 2 shows a schematic view of the test setup. Tests are performed on a $5000 \mathrm{kN}$ capacity hydraulic testing machine. Axial forces are applied on the bearing plate and the top endplate. Eight strain gauges are arranged on the symmetric axes of the mid-height section of the steel tube to measure the longitudinal and transverse strains. For all specimens, the axial deformations are collected by two linear voltage displacement transducers, as shown in Figure .2.

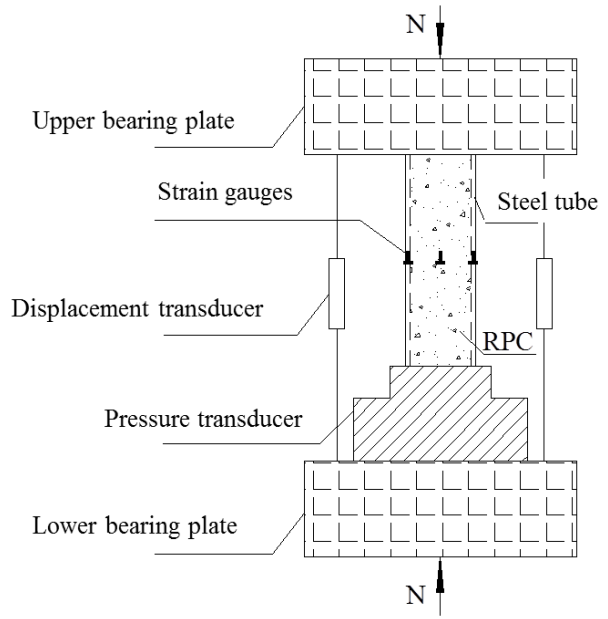

(a) Loading Diagram

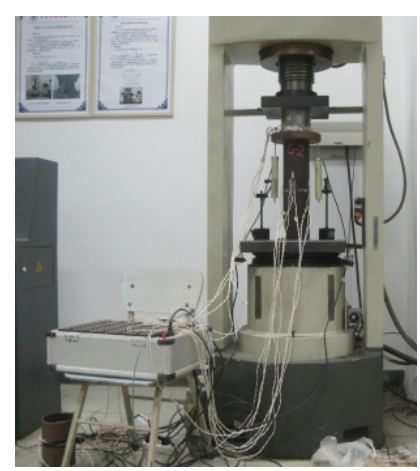

(b) Measuring Diagram

Fig. 2. Loading and measuring diagram

The interval load is applied. A load interval of less than one tenth the estimated load capacity is used before the steel is yielded, and less than one twentieth the estimated load 
Hua Luo, Weiwei Wang, Lian Shen and Guanghui Wang/

Journal of Engineering Science and Technology Review 10 (2) (2017) 122-131

capacity is used after the steel is yielded. Each load interval is maintained for approximately three minutes. The test data is collected by Donghua DH3816 static strain measuring system.

\subsubsection{Measurement content and layout of measuring points}

To explore the load-deformation law of the specimens, the following test contents should be included:

(1) Axial pressure at the top of the column;

(2) Displacement at the top of the column;

(3) Longitudinal and transverse strains on the symmetric axes of the mid-height section of the steel tube.

The performance of the columns is evaluated through an analysis of the measured data.

\subsection{Finite element analysis}

ABAQUS is used to analyze the performance of the specimens. In FEA, for the interface between the steel tube and the RPC, the normal direction contact is set as hard contact, and the tangential direction contact is taken as Coulomb friction model.

To determine the friction coefficient, the following assumptions are taken:

(1) The entire section yielded at peak load;

(2) The influence of thickness on the steel stress is ignored, and the longitudinal stress and circumferential stress along the thickness of the steel tube are identical;

(3) The friction between the steel tube and the RPC is greater than the adhesion, thereby resulting in slip at peak load.

Assuming friction coefficient as $\mu$, a micro-element $d x$ is considered for analysis, as shown in Figure.3. Where $\sigma_{\mathrm{zs}}$ is the longitudinal stress of the steel tube; $\sigma_{\theta \mathrm{s}}$ is the circumferential stress of the steel tube; $\sigma_{\text {rc }}$ is the radial stress of RPC.

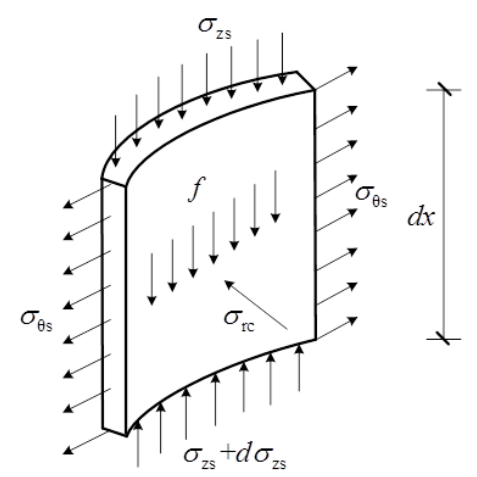

Fig. 3. Micro solid of steel tube

The friction $f$ between the steel tube and the RPC can be represented as follows:

$f=\mu \sigma_{\mathrm{rc}}$

The equilibrium equation, $\sigma_{r c} d_{c}=2 \sigma_{\theta s} t$, indicates that the friction equation of the column can be represented by the following equation:

$f=\mu \frac{2 \sigma_{\theta s} t}{d_{\mathrm{c}}}$
Where $d_{\mathrm{s}}$ is the diameter of RPC.

The equilibrium equation of the micro-element $d x$ can be represented as follows:

$\pi D t \sigma_{\mathrm{zs}}+\pi D f d x=\pi D t\left(\sigma_{\mathrm{zs}}+d \sigma_{\mathrm{zs}}\right)$

Eq. (3) can be simplified as follows:

$f d x=t d \sigma_{\mathrm{zs}}$

Substituting Eq. (2) into Eq. (4) obtains

$\mu \frac{2 \sigma_{\theta \mathrm{s}} t}{d_{\mathrm{c}}} d x=d \sigma_{\mathrm{zs}}$

Integral is performed for Eq. (5)

$\int_{0}^{x} \mu \frac{2 \sigma_{\theta \mathrm{s}}}{d_{\mathrm{c}}} d x=\int_{0}^{x} d \sigma_{\mathrm{zs}}$

The yield criterion $\sigma_{\mathrm{zs}}^{2}+\sigma_{\theta \mathrm{s}}^{2}+\left(\sigma_{\mathrm{zs}}-\sigma_{\theta \mathrm{s}}\right)^{2}=2 f_{\mathrm{y}}^{2}$ can be expressed as follows:

$\sigma_{\theta \mathrm{s}}=\frac{\sigma_{\mathrm{zs}}+\sqrt{4 f_{\mathrm{y}}^{2}-3 \sigma_{\mathrm{zs}}^{2}}}{2}$ (6)

The following is obtained by substituting Eq. (7) into Eq.

$\int_{0}^{x} \frac{\sigma_{\mathrm{zs}}+\sqrt{4 f_{\mathrm{y}}^{2}-3 \sigma_{\mathrm{zs}}^{2}}}{2} d x=\frac{d_{\mathrm{c}}}{2 \mu} \sigma_{\mathrm{zs}}$

$v=\sigma_{\mathrm{zs}} / f_{\mathrm{y}}$ is substituted into Eq. (8) as follows:

$\int_{0}^{x} v+\sqrt{4-3 v^{2}} d x=\frac{d_{\mathrm{c}}}{\mu} v$

Eq. (9) is simplified, and derivation is performed on it as follows:

$\left(\frac{d_{\mathrm{c}}}{\mu} \frac{d v}{d x}-v\right)^{2}+3 v^{2}=4$

Assuming $\frac{d_{\mathrm{c}}}{\mu} \frac{d v}{d x}-v=2 \cos t, \sqrt{3} v=2 \sin t$, the following equations are obtained

$\frac{d_{\mathrm{c}}}{\mu} \frac{d v}{d t} \frac{d t}{d x}-v=2 \cos t$

$v=\frac{2}{\sqrt{3}} \sin t$

$\frac{d v}{d t}=\frac{2}{\sqrt{3}} \cos t$

Substituting Eq. (12) and Eq. (13) into Eq. (11) obtains

$\frac{d_{\mathrm{c}}}{\mu} \frac{2}{\sqrt{3}} \cos t \frac{d t}{d x}-\frac{2}{\sqrt{3}} \sin t=2 \cos t$ 
Hua Luo, Weiwei Wang, Lian Shen and Guanghui Wang/

Journal of Engineering Science and Technology Review 10 (2) (2017) 122-131

Simplifying Eq. (14) as follows

$$
\frac{d x}{d t}=\frac{d_{\mathrm{c}}}{\mu} \frac{1}{\tan t+\sqrt{3}}
$$

Solving Eq. (15) as follows:

$$
\left\{\begin{array}{l}
x=\frac{d_{\mathrm{c}}}{\mu}\left[\frac{\ln (\tan t+\sqrt{3})}{4}-\frac{\ln \left[1+(\tan t)^{2}\right]}{8}+\frac{\sqrt{3} t}{4}-\frac{\ln \sqrt{3}}{4}\right] \\
y=2 \sin t / \sqrt{3}
\end{array}\right.
$$

The friction coefficient is equal to 0.6 based on the test results.

For the boundary conditions, all degrees of freedom of the top and bottom surfaces are constrained except the axial degree of freedom at the top.

\section{Result Analysis and Discussion}

\subsection{Analysis on the failure mode}

Before the tests, the PTFE gaskets were placed on the top and the bottom surfaces of the specimens to reduce the hoop effect caused by friction. Fig.4 shows that the axial pressure failure modes of the specimen are ductile failure modes, and evident deformations are observed.

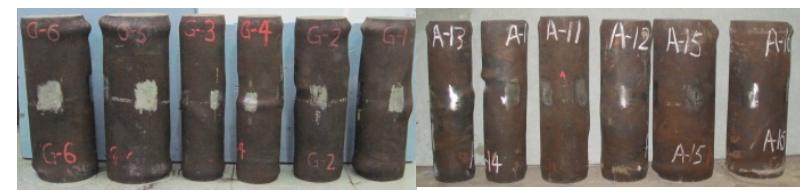

Fig. 4. Failure mode of specimens

In the beginning, the specimen is in the elastic phase. With the increase of the load, local yielding occurs in an unfavorable position, for instance, near the end of the column as a result of the edge effect, at a location with uneven thickness, or at a location with concentration stress. Oblique shear slip lines are first observed at the end of the columns when the steel tube yields, and the lines increase throughout the entire surface of the column with increasing load, as shown in Figure.5.
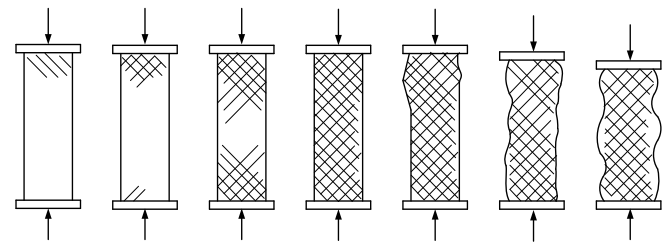

Fig. 5. Shear-slip development process of steel tube

\subsection{Analysis on the stress of steel tubes}

The steel tube is thin; thus, the stress-strain relationship is assumed to follow the 2D generalized Hooke's law as follows:

$$
\begin{gathered}
\sigma_{\mathrm{zs}}=\frac{E_{\mathrm{s}}}{1-v_{\mathrm{s}}^{2}}\left(\varepsilon_{\mathrm{zs}}+v_{\mathrm{s}} \varepsilon_{\theta \mathrm{s}}\right) \\
\sigma_{\theta \mathrm{s}}=\frac{E_{\mathrm{s}}}{1-v_{\mathrm{s}}^{2}}\left(\varepsilon_{\theta \mathrm{s}}+v_{\mathrm{s}} \varepsilon_{\mathrm{zs}}\right)
\end{gathered}
$$

where $E_{\mathrm{s}}$ is the elastic modulus of the steel, $\varepsilon_{\mathrm{zs}}$ is the longitudinal strain of the steel, $\varepsilon_{\theta \mathrm{s}}$ is the circumferential strain of the steel, and $v_{\mathrm{s}}$ is the Poisson's ratio of the steel.

If either steel tube or filled-in-concrete yields, then not only elastic strain is observed but also plastic strain. The strain values can be represented as follows:

$\varepsilon_{\mathrm{zs}}=\varepsilon_{\mathrm{zs}}^{\mathrm{e}}+\varepsilon_{\mathrm{zs}}^{\mathrm{p}}$

$\varepsilon_{\theta \mathrm{s}}=\varepsilon_{\theta \mathrm{s}}^{\mathrm{e}}+\varepsilon_{\theta \mathrm{s}}^{\mathrm{p}}$

where $\varepsilon_{\text {zs }}^{\mathrm{e}}$ is the longitudinal elastic strain of the steel, $\varepsilon_{z s}^{\mathrm{p}}$ is the longitudinal plastic strain of the steel, $\varepsilon_{\theta \mathrm{s}}^{\mathrm{e}}$ is the circumferential elastic strain of the steel, and $\varepsilon_{\theta s}^{\mathrm{p}}$ is the circumferential plastic strain of the steel.

The stress of the steel is related to the elastic strain only. Thus, the generalized Hooke's law can be represented as follows:

$$
\begin{gathered}
\sigma_{\mathrm{zs}}=\frac{E_{\mathrm{s}}}{1-v_{\mathrm{s}}^{2}}\left(\varepsilon_{\mathrm{zs}}^{\mathrm{e}}+v_{\mathrm{s}} \varepsilon_{\theta \mathrm{s}}^{\mathrm{e}}\right) \\
\sigma_{\theta \mathrm{s}}=\frac{E_{\mathrm{s}}}{1-v_{\mathrm{s}}^{2}}\left(\varepsilon_{\theta \mathrm{s}}^{\mathrm{e}}+v_{\mathrm{s}} \varepsilon_{\mathrm{zs}}^{\mathrm{e}}\right)
\end{gathered}
$$

The stress of the steel follows the following 2D von Mises yield criterion:

$\sigma_{\mathrm{zs}}^{2}+\sigma_{\theta \mathrm{s}}^{2}+\left(\sigma_{\mathrm{zs}}-\sigma_{\theta \mathrm{s}}\right)^{2}=2 f_{\mathrm{y}}^{2}$

The longitudinal stress-circumferential stress curves of the steel are shown in Figure.6.
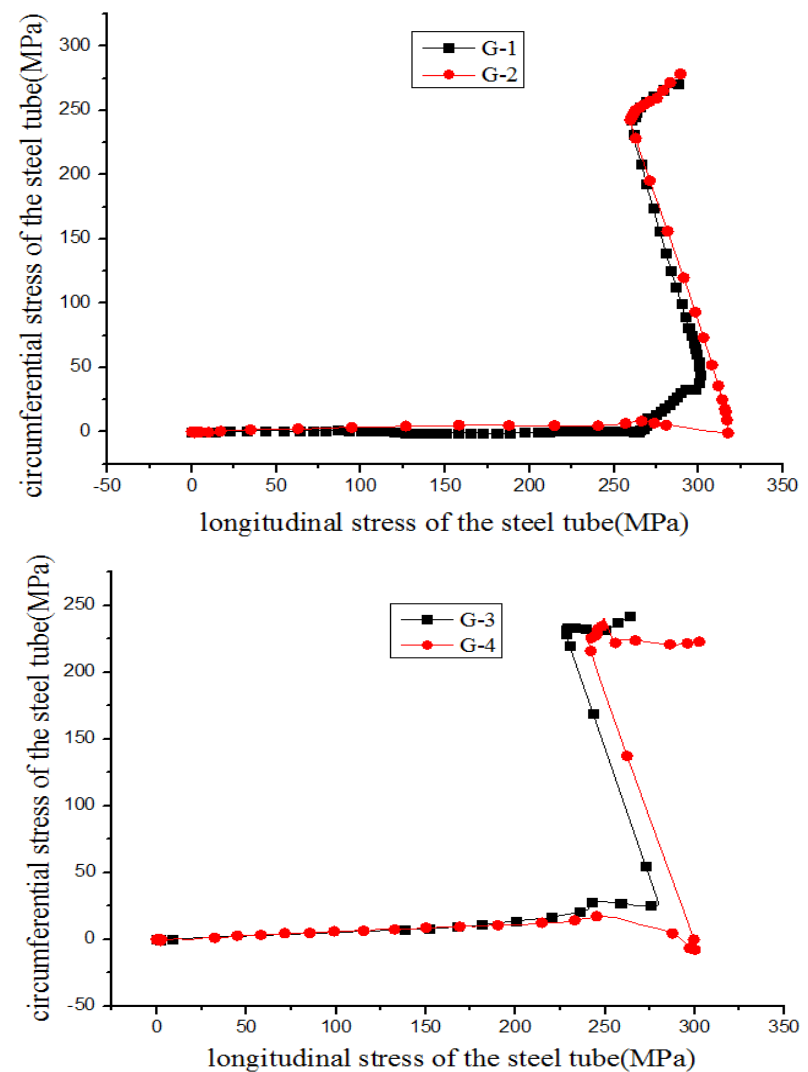


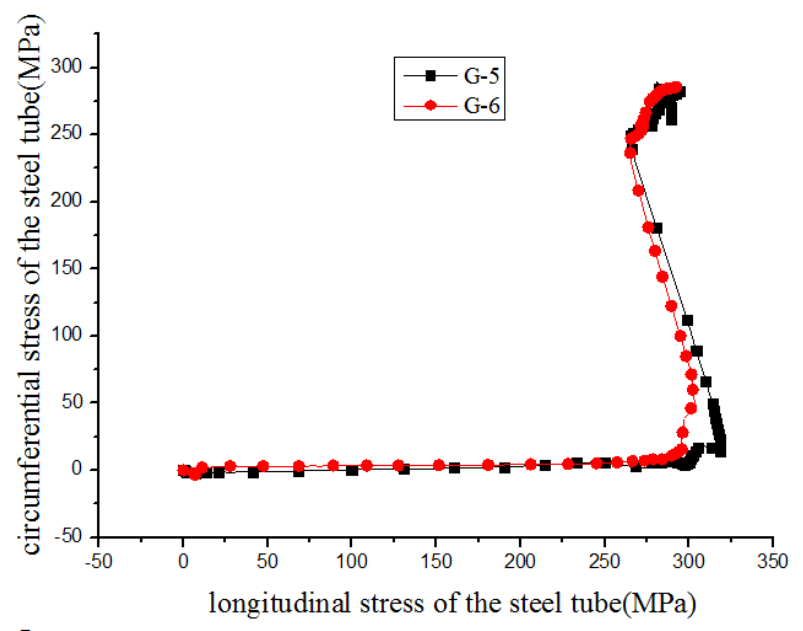

Figure 6 shows that the longitudinal stresscircumferential stress curves of the steel can be divided into the following three stages:

(1) Elastic phase. In the initial stage of loading, the load is small and the steel tube is in the elastic stage. The circumferential deformation of the steel tube is much smaller than that of the longitudinal deformation. The longitudinal stress and the circumferential stress increase linearly until the longitudinal stress of the steel tube reaches the yield strength.

(2) Elastoplastic stage. At this stage, the circumferential stress of the steel tube increases rapidly, and the longitudinal stress reduces slightly until the longitudinal stress of the steel tube is close to the longitudinal stress, which is approximately 200-250 MPa.

(3) Plastic strengthening stage. At this stage, the core RPC is destroyed, the external load is reduced, the load is supported by the residual strength of the steel tube and the core RPC, and the longitudinal stress and the circumferential stress of the steel tube increase proportionally.

\subsection{Stress-strain model for core RPC}

To obtain the $\sigma_{\mathrm{c}}-\varepsilon_{\mathrm{c}}$ curve of the core RPC, the steel tube is assumed to be in the plane stress state during the loading process where its radial stress is negligible.

The $\sigma_{\mathrm{c}}-\varepsilon_{\mathrm{c}}$ curves of all specimens are shown in Fig.7.

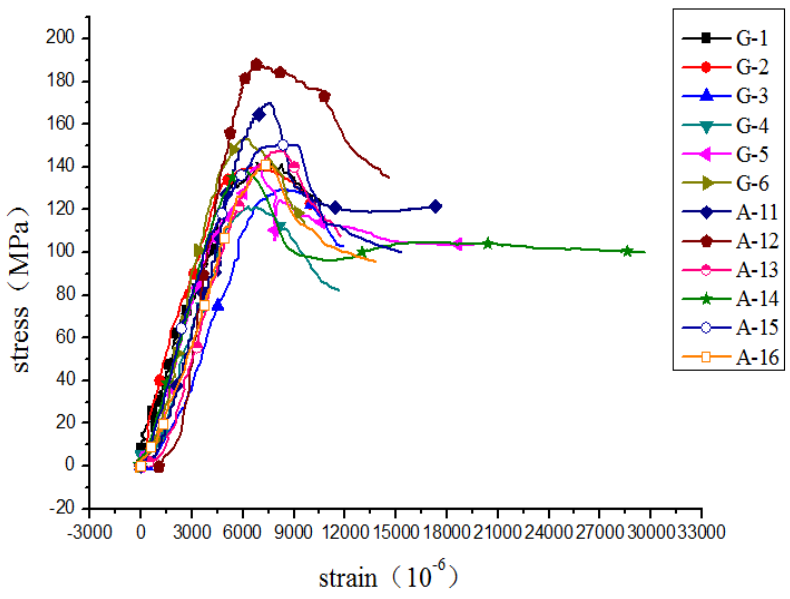

Fig. 7. Stress-strain curves for core RPC

Figure 7 shows that the stress-strain curve of the core RPC is similar to that of ordinary concrete. The geometric characteristics of the curves are as follows:

(1) The original point of the curve is $(0,0)$;

(2) The ascending segment of the curve increases monotonously with no inflection point;

(3) A single peak is observed;

(4) The descending segment of the curve has an inflection point.

The peak strength of the core RPC increases with the increase of $\xi$ and $f_{\mathrm{y}}$ when the compressive strength of the $\mathrm{RPC}$ is constant. When the compressive strength of the RPC is high, the peak strength of the core RPC is also high.

The confining pressure $\sigma_{\mathrm{r}}$, peak strain $\varepsilon_{0}$ and peak stress $f_{0}$ of the core RPC obtained from the tests are shown in Table 3 
Hua Luo, Weiwei Wang, Lian Shen and Guanghui Wang/

Journal of Engineering Science and Technology Review 10 (2) (2017) 122-131

Table 3. Peak strength of core concrete

\begin{tabular}{|c|c|c|c|c|c|c|c|c|}
\hline Specimen & $D \times t \times L / \mathrm{mm}$ & $f_{\mathrm{MPa}}$ & $D / t$ & $f_{\mathrm{c}}$ & $\xi$ & $\begin{array}{l}\sigma_{\mathrm{r}} \\
\mathrm{MPa}\end{array}$ & $\varepsilon_{0}$ & $f_{0}$ \\
\hline G-1 & \multirow{2}{*}{$121 \times 6 \times 450$} & \multirow{2}{*}{316.0} & \multirow{2}{*}{20.17} & \multirow{2}{*}{75} & \multirow{2}{*}{0.979} & 27.71 & 7356 & 142.85 \\
\hline G-2 & & & & & & 27.78 & 6667 & 139.65 \\
\hline G-3 & \multirow{2}{*}{$102 \times 4 \times 450$} & \multirow{2}{*}{291.4} & \multirow{2}{*}{25.50} & \multirow{2}{*}{75} & \multirow{2}{*}{0.689} & 25.74 & 8489 & 129.61 \\
\hline G-4 & & & & & & 25.05 & 6333 & 121.45 \\
\hline G-5 & \multirow{2}{*}{$152 \times 5 \times 450$} & \multirow{2}{*}{321.6} & \multirow{2}{*}{30.40} & \multirow{2}{*}{75} & \multirow{2}{*}{25} & 27.80 & 6844 & 139.85 \\
\hline G-6 & & & & & & 28.03 & 6244 & 153.27 \\
\hline A-11 & \multirow{2}{*}{$-121 \times 6 \times 450$} & \multirow{2}{*}{316.0} & \multirow{2}{*}{20.17} & \multirow{2}{*}{100} & \multirow{2}{*}{0.734} & 26.59 & 7450 & 170.00 \\
\hline A-12 & & & & & & 32.85 & 6667 & 189.34 \\
\hline A-13 & \multirow{2}{*}{$102 \times 4 \times 450$} & \multirow{2}{*}{291.4} & \multirow{2}{*}{25.50} & \multirow{2}{*}{100} & \multirow{2}{*}{0.517} & 14.43 & 8267 & 147.55 \\
\hline A-14 & & & & & & 15.30 & 6111 & 138.18 \\
\hline A-15 & \multirow{2}{*}{$152 \times 5 \times 450$} & \multirow{2}{*}{321.6} & \multirow{2}{*}{30.40} & \multirow{2}{*}{100} & \multirow{2}{*}{0.469} & 28.39 & 8533 & 150.43 \\
\hline A-16 & & & & & & 26.35 & 7400 & 141.45 \\
\hline
\end{tabular}

Table. 3 shows that the confining pressure varies from 14.43 $\mathrm{MPa}$ to $32.85 \mathrm{MPa}$; thus, the core RPC is in a low confining pressure state. In addition, the confining pressure increases with the increase in the hoop coefficient and the yield strength of the steel. The peak strain and peak stress of the core RPC are influenced differently by the yield strength of the steel and the hoop coefficient.

In this study, the uniaxial compressive peak strain formula for RPC presented by Yanhai and Yanbin [24] is taken as follows:

$\varepsilon_{\mathrm{cc}}=286.760+22.084 f_{\mathrm{c}} \quad(\mu \varepsilon)$

The peak stress and peak strain of the core RPC are assumed to be as follows:

$$
\begin{aligned}
& \frac{f_{0}}{f_{\mathrm{c}}}=a+b \xi+k_{1} \frac{f_{\mathrm{y}}}{f_{\mathrm{c}}} \\
& \frac{\varepsilon_{0}}{\varepsilon_{\mathrm{cc}}}=c+d \xi+k_{2} \frac{f_{\mathrm{y}}}{f_{\mathrm{c}}}
\end{aligned}
$$

where $a, b, c, d, k_{1}$, and $k_{2}$ are constants, $\varepsilon_{\mathrm{cc}}$ is the peak strain of RPC under uniaxial compression, $f_{\mathrm{c}}$ is the axial compressive strength of RPC.

The peak stress data are plotted in Figure.8.

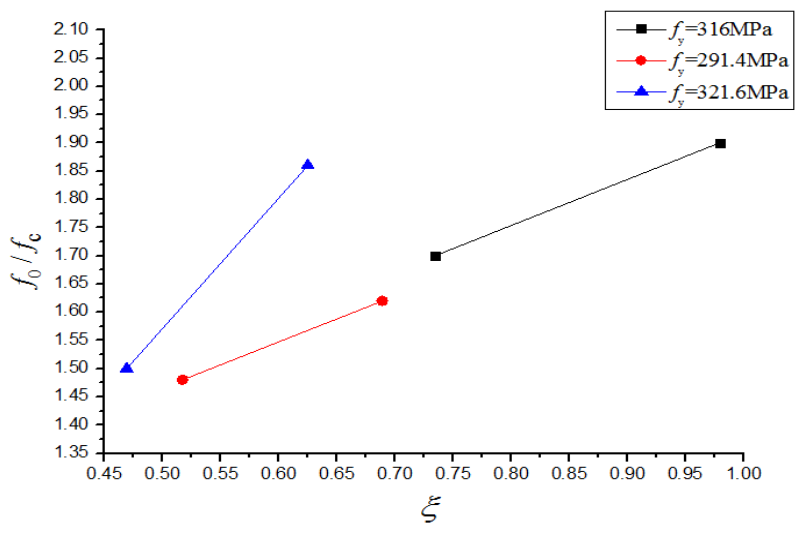

Fig. 8. $f_{0} / f_{\mathrm{c}}-\xi$ curve
The data are fitted by using the following equation:

$$
\frac{f_{0}}{f_{\mathrm{c}}}=0.345+0.815 \xi+0.209 \frac{f_{\mathrm{y}}}{f_{\mathrm{c}}}
$$

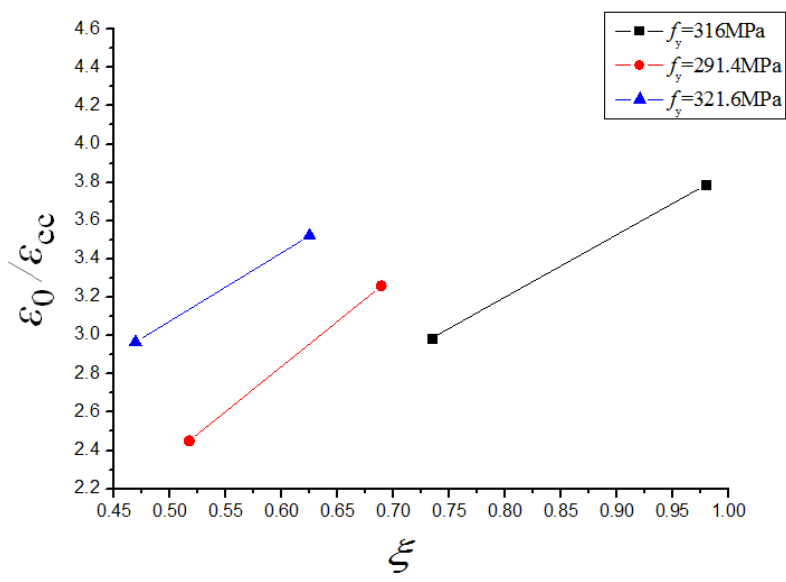

Fig. 9. $\varepsilon_{0} / \varepsilon_{\mathrm{cc}}-\xi$ curve

The data are fitted by using the following equation:

$$
\frac{\varepsilon_{0}}{\varepsilon_{\mathrm{cc}}}=3.265 \xi+0.312 \frac{f_{\mathrm{y}}}{f_{\mathrm{c}}}-0.029
$$

The experimental data indicate that the stress-strain curves of the core RPC are measured with dimensionless coordinates as, $x=\frac{\varepsilon_{\mathrm{c}}}{\varepsilon_{\mathrm{pr}}}, y=\frac{\sigma_{\mathrm{c}}}{\sigma_{\mathrm{pr}}}$,where $\varepsilon_{\mathrm{pr}}$ is the peak compressive strain, and $\sigma_{\mathrm{pr}}$ is the peak compressive stress. The stress-strain model for core RPC, which is based on the constrained concrete model proposed by Han Linhai and Mander, is expressed as follows:

$$
y= \begin{cases}x[a(x-1)+1] & (x \leq 1) \\ \frac{x}{\beta(x-1)^{2}+x} & (x \geq 1)\end{cases}
$$

The test data reveal that the relationship among $\alpha, \beta$, and $\xi$ is as shown in Figs. 10 and Figs. 11.

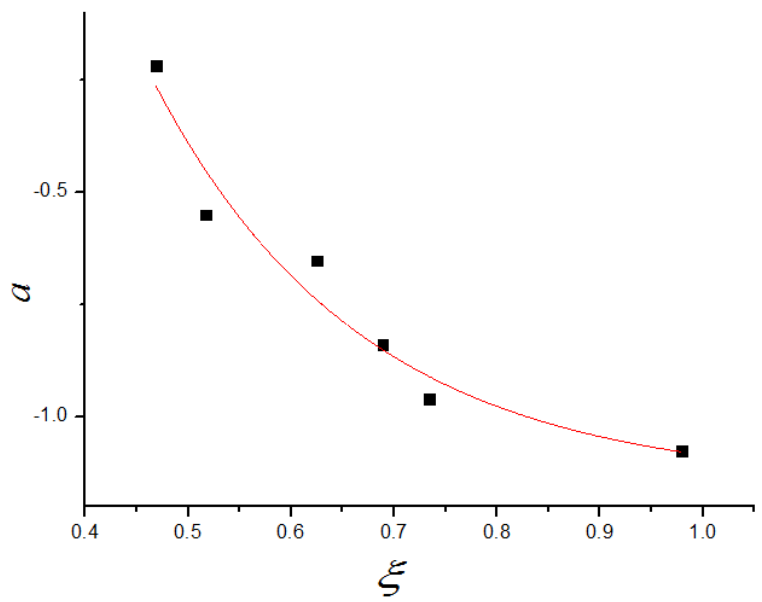

Fig. 10. $\alpha-\xi$ curve

The data are fitted by using the following equation: 
Hua Luo, Weiwei Wang, Lian Shen and Guanghui Wang/

Journal of Engineering Science and Technology Review 10 (2) (2017) 122-131

$a=-1.150+8.970 \times 0.007^{\xi}$

(28)

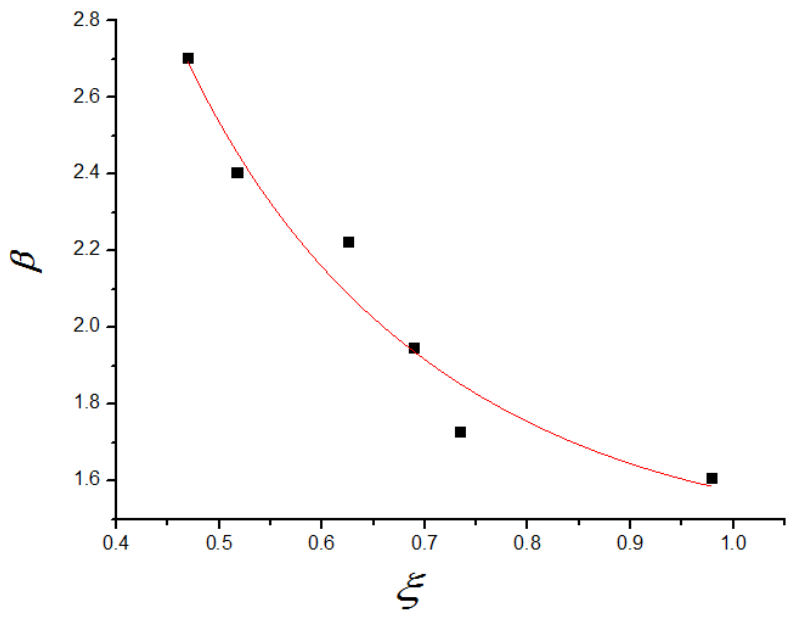

Fig. 11. $\beta$ - $\xi$ curve

The data are fitted by using the following equation:

$$
\beta=1.421-8.584 \times 0.017^{\xi}
$$

\subsection{Comparison between the FEA results and} experimental results

Comparisons between the load-strain test curves and the FEA results are shown in Fig. 12.
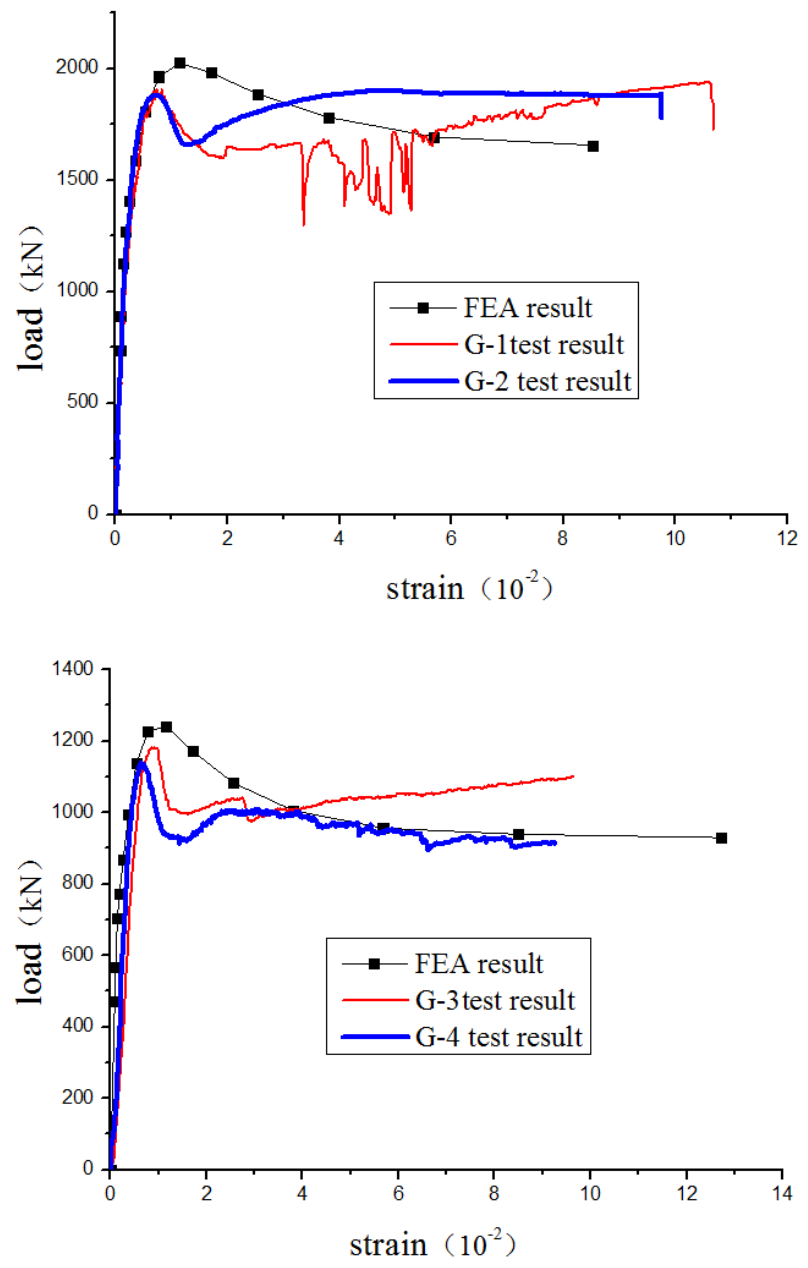
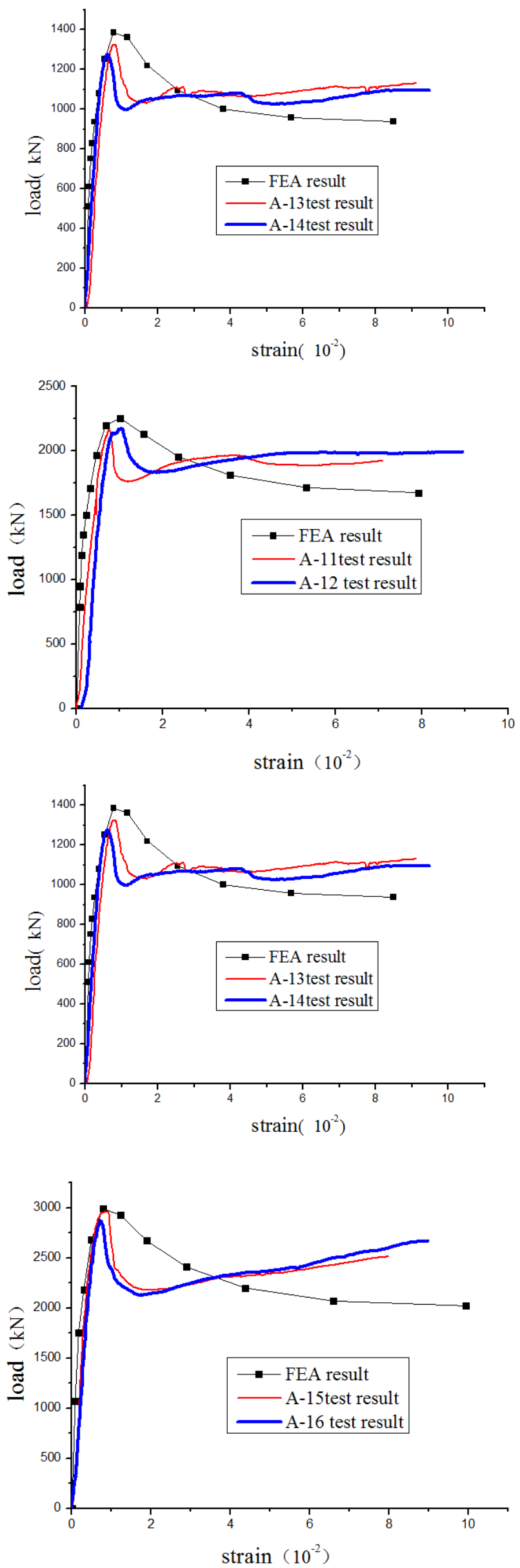

Fig. 12. Load-strain curves of experimental and FEA results 
Fig.12 shows that the tested load-strain curves are approximate to those of the calculated at the ascending segment. Moreover, the peak strains are well matched. However, the curves deviated slightly after the peak mainly because of the following reasons: (1) the influence of materials, that is, the stability of materials is poor and the dispersion is large, thereby leading to the discrepancy (2) the boundary conditions of FEA are different from those of the experimental conditions.

\section{Conclusions}

To analyze the performance of RPC-filled steel tube structures comprehensively with the numerical analysis method, experimental research was conducted on the RPCfilled steel tube columns. The confining pressure was analyzed based on this research. Stress-strain curves for the core RPC were derived, and a confined stress-strain model for core RPC was proposed. The following conclusions were drawn:

(1) Longitudinal-circumferential stress development of steel tube generally undergoes three stages: elastic, elastoplastic, and plastic strengthening stages.

(2) The stress-strain curve of core RPC is similar to that of ordinary concrete, and the peak strength of core RPC increases with the increasing steel yield strength, hoop coefficient, and axial compressive strength of RPC.

(3) The force transmission characteristics between steel tube and core RPC are analyzed, and the friction coefficient is taken as 0.6 in FEA.

(4) A constitutive relation for the core RPC, which is applicable to FEA, is proposed based on the experimental data. A comparison between the load-strain test curves and the FEA results shows that the new constitutive model is reasonable and applicable to RPC-filled steel tube structure analysis.

Thus, the proposed constitutive model for the confined RPC has a clear concept and a simple formation, and the unknown parameters can be confirmed easily in FEA. Moreover, the proposed model can predict the ultimate load and peak strain of the RPC-filled steel tube column, thereby enabling further analysis of the working performance of the RPC-filled steel tube structure in the complex mechanical state. However, because the model requires some material parameters, and the performance of RPC varies significantly with different mixtures of composition material, certain deviation of the parameters in the actual condition would occur. Therefore, future studies should consider more parameters that influence the performance of the material to expand the application of the model and to further investigate the performance of the RPC-filled steel tube structure in a complex stress state.

\section{Acknowledgements}

This work was supported by the National Basic Research Program of China 973 Plan (project no. 2015CB057701), the Program of Hunan Provincial Education Department (project no. 16C0725), the Project of College Students in Hunan Province (project no.[2016]96,201610543005).

This is an Open Access article distributed under the terms of the Creative Commons Attribution Licence

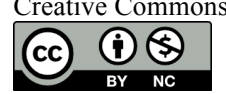

\section{References}

1. Xia, H., Shi, Z., Wang, W., "Mechanical properties of reactive powder concrete with ultra-short brass-coated steel fibers". Magazine of Concrete Research, 67(6), 2015, pp.308-316.

2. Gökçe, H. S., Sürmelioğlu, S., Andiç-Cakir, Ö., "A new approach for production of reactive powder concrete: lightweight reactive powder concrete (LRPC)". Materials and Structures, 50(1) ,2017, pp.58.

3. Ahmad, S., Zubair, A., Maslehuddin, M., "Effect of key mixture parameters on flow and mechanical properties of reactive powder concrete". Construction \& Building Materials, 99(11) , 2015, pp.73-81.

4. Hua, L., Wen-Yu, J. I., Yan, Z. G., et al., "Research on influence of loading methods on compressive behavior of reactive powder concrete filled steel tube stub columns under axial loads". Journal of the China Railway Society, 36(9) , 2014, pp.105-110.

5. Yan, Z., Luo, H., and An. M., "A study of the bond behavior of the interface of reactive powder concrete filled steel tube columns". China Civil Engineering Journal, 43(8), 2010, pp.57-62.

6. Piscesa, B., Attard, M. M., Samani, A. K., et al., "Plasticity constitutive model for stress-strain relationship of confined concrete". ACI Structural Journal, 114(2), 2017, pp. 361.

7. Chen, W. F., "Plasticity in reinforced concrete". J. Ross Publishing, 2007.

8. Lu D, Du X, Wang G, et al., "A three-dimensional elastoplastic constitutive model for concrete". Computers \& Structures, 163(8),2016, pp.41-55.

9. Bazant, Z. P., Kim, S. S., "Plastic - fracturing theory for concrete". Journal of the Engineering Mechanics Division, 105, 1979, pp.407428.

10. Zdeněk, P., Bažant, Ching, L., "Endochronic model for nonlinear triaxial behavior of concrete". Nuclear Engineering \& Design, 47(2), 1978, pp.305-315.

11. Min, Y. U., Zha, X., Jianqiao, Y. E., et al., "A unified formulation for circle and polygon concrete-filled steel tube columns under axial compression". Engineering Structures, 49(2), 2013, pp.1-10.
12. Ji, W., Luo, H., Yang, G., "Experimental research on mechanical behavior of axially loaded RPC filled circular steel tube slender column". Zhongguo Tiedao Kexue/china Railway Science, 35(1), 2014, pp.28-33.

13. Wang, J., Chen, W., Guo, Z., et al., "Dynamic responses of RPCfilled steel tubular columns post fire under blast loading". Open Civil Engineering Journal, 10(1), 2016, pp.236-245.

14. Chen, W., Guo, Z., Zhang, T., et al., "Near-field blast test on Reactive Powder Concrete-Filled Steel Tubular columns after exposure to fire". International Journal of Protective Structures, 7(2), 2016, pp.193-212.

15. Zou, H. H., Chen, W. X., Guo, Z. K., et al., "Tests for blastresistant capacities of RPC filled steel tubular columns after exposure to fire". Journal of Vibration and Shock, 35(13), 2016, pp.1-7.

16. Prabha, S. L., Dattatreya, J. K., Neelamegam, M., et al., "Study on stress-strain properties of reactive powder concrete under uniaxial compression". International Journal of Engineering Science \& Technology, 2(11), 2010, pp.6408-6416.

17. Zheng, W., Li, H., Wang, Y., "Compressive stress-strain relationship of steel fiber-reinforced reactive powder concrete after exposure to elevated temperatures". Construction \& Building Materials, 35(10), 2012, pp.931-940.

18. Zheng, W., Luo, B., Wang, Y., "Stress-strain relationship of steelfiber reinforced reactive powder concrete at elevated temperatures". Materials and Structures, 48(7), 2015, pp.1-16.

19. Yu, Z., Qing, X., An, M., "Experimental research on the conventional triaxial compressive properties of reactive powder concrete". China Railway Science, 33(2), 2012, pp.38-42.

20. Wang, Y. B., Liew, J. Y. R., Lee, S. C., et al., "Experimental study of ultra-high-strength concrete under triaxial compression". Aci Materials Journal, 113(1), 2016, pp.105-112.

21. Noori, A., Shekarchi, M., Moradian, M., et al., "Behavior of steel fiber-reinforced cementitious mortar and high-performance concrete in triaxial loading". Aci Materials Journal, 112(1), 2015, pp.95-104.

22. Wu, H., Cao, W., Qiao, Q., et al., "Uniaxial compressive constitutive relationship of concrete confined by special-shaped steel tube coupled with multiple cavities". Materials, 9(2), 2016, pp.86. 
Hua Luo, Weiwei Wang, Lian Shen and Guanghui Wang/

Journal of Engineering Science and Technology Review 10 (2) (2017) 122-131

23. Lai, M. H., Ho, J. C. M. "A theoretical axial stress-strain model for circular concrete-filled-steel-tube columns". Engineering Structures, 125,2016, pp.124-143
24. Wu Y. H., He Y. B.,Yang Y. H., "Investigation on RPC200 mechanical performance". Journal of Fuzhou University (Natural Science Edition). 5(31), 2003, pp.598-602. 